\title{
IMAGEN Y TEXTO EN MANUSCRITOS BÍBLICOS HISPÁNICOS
}

\author{
Gemma Avenoza \\ Universitat de Barcelona - IRCVM \\ gavenoza@ub.edu
}

Todo libro medieval surge para cubrir una necesidad. El pergamino es caro y puede escasear y aunque se trate de un ejemplar en papel, no podemos olvidar que el trabajo de copia requiere la participación de profesionales cualificados y que se demora durante meses; además, si el texto va acompañado de imágenes, intervendrán otras manos para realizar las miniaturas y aplicar el oro y los colores. Todo un proceso largo y costoso, que ha de cumplir con las expectativas de quien hizo el encargo inicial.

La necesidad concreta que dio inicio a ese proceso determina las características del libro. No será lo mismo que en un monasterio se necesiten nuevas copias de lecturas piadosas para los monjes en sus celdas, que un cantoral para los oficios más solemnes. No será lo mismo que en Bolonia o Salamanca un estudiante copie un Graciano para seguir a sus maestros, alquilando pecia tras pecia, con prisa y minimizando el gasto (por ejemplo London, British Library, Harley 3256 del último cuarto del s. XII) ${ }^{1}$, que un jurisconsulto encargue una copia lujosa del Graciano (por ejemplo, Cambridge, Fitzwilliam Museum, Marlay Cuttings It. 3-11, copiado e iluminado en Bolonia ca. 1320)

\footnotetext{
${ }^{*}$ Este estudio se inscribe en el proyecto financiado por el Ministerio de Economía y Competitividad FFI2014-55537-C3-1-P y su desarrollo sigue las líneas investigación del Grup de Recerca Consolidat de la Generalitat de Catalunya 2014SGR51.

${ }^{1}$ Cfr. <http://www.bl.uk/catalogues/illuminatedmanuscripts/record.asp?MSID=4208> [Consulta: 1/3/2016]. De esos manuscritos copiados por el sistema de pecia se hicieron después copias de mejor calidad, de las cuales puede verse un ejemplo en el comentario a las Decretales del Papa Gregorio IX por Henricus Ostiensis, códice en pergamino del s. XIII conservado en London, British Library, Arundel 485, en cuyo f. 296v se puede ver la indicación de pecia procedente de su original.
} 
o que solicite otra copia sobre la que trabajar y añadir sus propias glosas y anotaciones $^{2}$.

Todos esos libros tendrán en común un nivel de legibilidad y cuidado en su presentación acordes con la función que han de cumplir. Han de satisfacer las expectativas de sus destinatarios y servir para las funciones para las que fueron creados. No todos tendrán ilustraciones, pero no le faltarán a ninguno si las exige la comprensión del texto y su calidad dependerá de la necesidad que el libro venga a cubrir. Pongamos un ejemplo muy corriente: los libros de albeitería. La mayoría lleva el dibujo de un caballo con los signos del zodíaco distribuidos sobre su cuerpo y algunos incluyen representación de los instrumentos quirúrgicos ${ }^{3}$. Pueden incluir sólo bocetos (a tinta o punta de carbón) o pinturas obra de artistas que no escatiman oro y plata en las representaciones de los planetas. Todos cumplen con una exigencia de los materiales destinados a la praxis, ya que sin ellos el texto no es suficiente para transmitir su contenido y responder a la necesidad que le dio origen.

Hay obras que por sí mismas son suficientes para cumplir su función y cuando se planean no se piensa en añadirles ilustraciones. Son volúmenes sencillos, sin ningún valor de representación y no tienen detrás la exigencia de un bibliófilo o de un poseedor que exija de ellos una bella apariencia. Su programa iconográfico no va más allá de incorporar rúbricas en rojo o algunas anotaciones en ese mismo color en los márgenes para facilitar la rápida localización de los pasajes. Resulta, sin embargo, que tras concluirse la copia alguien decide incorporarles ilustraciones aprovechando los espacios de los márgenes, como sucedió con el manuscrito del segundo tercio del s. XV de la Ceremonias de la orden de san Benito del Monasterio de San Millán de la Cogolla, cód. A 114/5.24. Esas ilustraciones, carentes de interés artístico y

${ }^{2}$ Ejemplo de un encargo de manuscrito iluminado al que se añaden después notas de trabajo es el ms. Ludwig XIV: 2 (1170-1180 ca.) hoy en Los Angeles, Getty Center, que se ha vinculado a códices copiados en París para los miembros de la corte de Thomas Becket en el exilio, vid. Leena Löfstedt, «The Ms. Ludwig XIV: 2 (The 'Getty Gratian') and the old french Decretum translation», Romanica Cracoviensia, 15 (2015), pp. 192-215.

${ }^{3}$ València, Biblioteca Històrica Universitària ms. 624 incluye una ilustración a toda página que representa un caballo con los signos del zodíaco distribuidos por su cuerpo (BITECA manid 1826). En ejemplares destinados a grandes personajes, como lo fue probablemente el que se encuentra hoy en New Haven, Yale Univ. Beinecke Rare Book and Manuscript Library MS 454, llegamos a encontrar tres dibujos de caballos, 65 diagramas y una miniatura que representa al rey Alfonso el Magnánimo con sus armas montado en un caballo con las patas delanteras alzadas (BITECA manid 2013). Por su carácter práctico y no meramente suntuario encontramos también ilustraciones en las ediciones, por ejemplo en la de Barcelona, por Dimas Ballester para Joan Giglo de 1523 (BITECA manid 2523). BITECA = Gemma Avenoza, Lourdes Soriano y Vicenç Beltran, Bibliografia de textos catalans antics, Enlace: <www.bancroft.berkeley.edu/Philobiblon/Biteca> Berkeley, The Bancroft Library [Consulta: 1/03/2016].

${ }^{4}$ BETA manid 5623, contiene dos obras: [1] ff. 1-109: Ceremonias [de la orden de san Benito]; [2] ff. 114-131 foliación moderna: Señales para emplear cuando se debe guardar silencio. BETA = Charles B. 
obra de mano muy poco diestra, establecen con el texto un diálogo estrecho y lo complementan. Veamos un ejemplo. En los ff. 33v-34r se explica cómo se distribuyen los libros a los monjes para su lectura al inicio de la cuaresma, y en la página siguiente se menciona el castigo que recibirá quien no cumpla con el precepto.

E después que fuere leída la Regla, en la qual se leerá el capítulo de la guarda de la quaresma, el cantor o otro al qual él lo encomendare, póngasse a los pies del prior asentado e lea el scripto en que están escritos los nombres de los monjes que tovieron los libros el año passado. E quando leyere el nombre de cada monje, ponga esse monje el libro que tovo en el tapete con los otros e bese la mano al prior. Después d'esto tome el prior para si la regla de nuestro padre san Benito e dende mande dar a cada uno el libro que judgare que le conviene, segunt su abilidad de cada uno. E los cantores amos den los libros a los monjes que mandare el prior. El uno a la una parte e el otro a la otra. E es de guardar que cada un monje a quien fuere dado el libro ${ }^{[\mathrm{f} .34]}$ faga su inclinación e descubra la su cabeça. E mientra estas cosas sobre dichas se hazen, el monje que escrive e lee a de escrevir los nombres de los monjes que reciben los libros. Aquesto es: tal monje reçibió tal libro. Después d'esto los cantores váyanse a asentar. E luego los libros que quedaron que non se dieron sean puestos a recabdo. E los que non leyeron los libros el año passado fagan las venias e sean corregidos muy gravemente, lo qual quede en alvedrío del prior (ff. $33 \mathrm{v}-34 \mathrm{r})^{5}$.

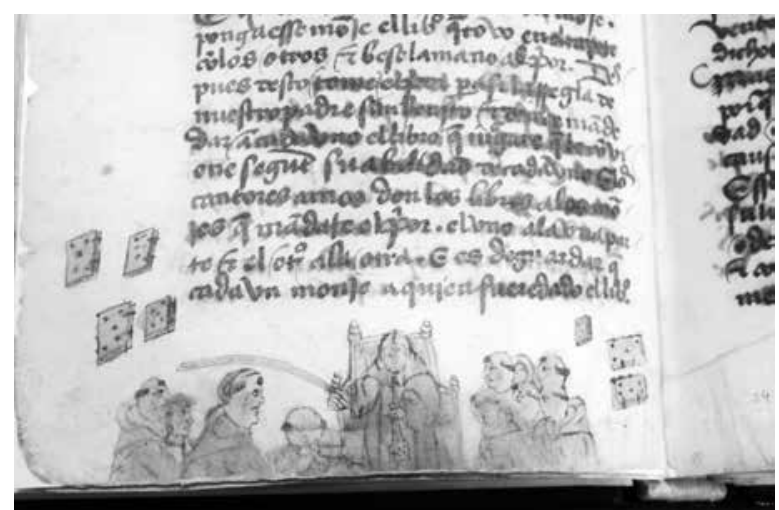

[1] San Millán, Biblioteca del Monasterio, cód. A 114/5.2 f. 33v

(C) Monasterio de San Millán de la Cogolla

Faulhaber, Bibliografia española de textos antiguos. Enlace: <www.bancroft.berkeley.edu/Philobiblon/ Beta> Berkeley, The Bancroft Library [Consulta: 01/03/2016].

${ }^{5}$ Salvo aquellos que se encuentran en Andrés Enrique-Arias (ed.), Biblia medieval, Palma de Mallorca, Univ. Illes Balears, 2009. Enlace: <http://www.bibliamedieval.es/> [Consulta: 1/3/2016], y las glosas del Gé, el resto de textos citados proceden de nuestras propias transcripciones. En todas las citas hemos introducido puntuación y acentuación, normalizado el uso de i/j, u/v y adecuado la separación de palabras a los usos actuales, sin realizar ninguna otra modificación. 
En el margen inferior del f. $33 \mathrm{v}$ está representada la escena y todos sus actores. En el centro el abad que aplica la disciplina al grupo de monjes que están a su derecha. Por toda la imagen, en tamaño mayor del que les correspondería en contraste con las figuras humanas, aquí y allá destacan los libros objeto del reparto, y en el centro mismo de la composición, sostenido por la mano izquierda del abad un libro de cintura, con toda certeza la Regla de san Benito, que se acaba de leer y por cuya autoridad él aplica el castigo.

El libro no se pensó para ser ilustrado, pero alguien lo consideró necesario. ¿Por qué? Todas las ceremonias representadas se repetían año tras año y los monjes las conocían. Esas imágenes sólo serían necesarias si el libro estuviera destinado a alguien ajeno a la liturgia y usos de la orden y deseara familiarizarse con ellos, pero esta explicación se contradice con que la parte del manuscrito destinada a los signos que se emplean cuando los monjes se comunican en silencio no disponga de ningún tipo de ilustración. Los dibujos añadidos en los márgenes de las Ceremonias han de responder a otra razón (ff. 114r-130r).

Es de notar que en casi la mitad de las ceremonias ilustradas existe una relación entre la ceremonia y los libros y en otras siete podría haber sido necesaria su presencia. Los paratextos que acompañan al manuscrito sugieren que este volumen permanecía en la biblioteca del monasterio y que estuvo en uso por largo tiempo. Si no fuera un libro manejado por el monje responsable de los libros ${ }^{6}$, raramente podríamos encontrar en él anotaciones como las que se añadieron en el f. 110 antiguo $=109$ moderno, originalmente en blanco, y que se refieren a monjes y libros que se les prestaron o que «concedieron al convento», realizadas en 1540 y 1541 . Sumando las características de los paratextos con las de las imágenes proponemos la hipótesis siguiente: las ilustraciones fueron realizadas por o para alguien especialmente sensible a los libros y a su presencia (o ausencia) en las ceremonias de la orden. Este perfil encaja con el del responsable de la guarda de los libros ya que le podía servir de guía sobre las ceremonias en las que debían estar presentes y aquellas en las que no eran necesarios. Una hipótesis alternativa, aunque no excluyente de la anterior, sería que las ilustraciones tuvieran como función resaltar la importancia del libro en la vida monástica benedictina.

\footnotetext{
${ }^{6}$ Recordemos que la regla de san Benito prohibe que los monjes tengan posesiones: «Que los monjes non deven aver propio. Capítulo XXXIII. [...] que ninguno non sea osado de dar o de tomar alguna cosa sin mandado de su abat, nin aver ninguna cosa propria de todo en todo: nin libro, nin tablas, nin grafio, mas de todo en todo ninguna cosa». La regla de San Benito. Traducción castellana del siglo XV para uso de los monasterios de San Millán y Silos, ed. de Miguel C. Vivancos Gómez y Fernando Vilches Vivancos, Logroño, Instituto de Estudios Riojanos, 2001, p. 101.
} 
El programa iconográfico original de las Ceremonias de la orden de san Benito era austero, reducido a las rúbricas e iniciales y las miniaturas añadidas tienen un papel meramente utilitario, no de enriquecimiento artístico. No es un manuscrito a incluir en un estudio sobre el arte de la miniatura en la edad media hispánica, pero es un ejemplo de cómo la ilustración establece un diálogo con el texto y aparece, incluso en libros relativamente modestos, cuando es necesaria para dar respuesta a una necesidad específica, que no siempre resulta evidente a primera vista.

Analizaremos un pequeño grupo de manuscritos bíblicos castellanos a partir de este enfoque, que entiende las miniaturas de un códice no solamente como formas de embellecimiento material, sino también como elementos surgidos para colmar determinadas expectativas de los patrones que encargaron los libros -más allá de la exigencia artística-, o para servir de expresión iconográfica a un pensamiento que no se expresa con palabras nacido del entorno en el que se produjo la copia e iluminación del manuscrito.

En contraste con las Ceremonias de San Millán de la Cogolla, los manuscritos que forman el corpus de análisis que hemos escogido -Esc. I-I-4, I-I-7, I-I-5 y la Biblia de Arragel (también conocida como Biblia de Alba o Biblia de D. Luis de Guzmán- poseen programas iconográficos de cierta complejidad, que fueron ejecutados por miniaturistas profesionales ${ }^{7}$. Acudimos a estos manuscritos iluminados porque comparten un buen número de elementos: la época (s. Xv), el lugar de creación (reino de Castilla), el material (pergamino), la lengua (el castellano), las características textuales (todos son traducciones bíblicas del hebreo realizadas por conversos o judíos) y la condición de sus patronos (importantes personajes de la nobleza cristiana). Cada uno de esos códices, además, representa un estadio distinto por lo que respecta a la relación del texto con sus ilustraciones y en todos los casos se establece un diálogo entre el patrón y la obra que espera recibir, que condiciona el proceso de copia e iluminación. Son encargos de precio elevado en los que hubo una intención concreta de vincular la obra a la casa a la que estaba destinado (por la presencia de escudos en las orlas -Esc. I-I-4-, o representación del patrón -Biblia de Arragel-, por ejemplo) ${ }^{8}$.

${ }^{7}$ En Esc. I-I-4 intervinieron probablemente varios miniaturistas, $c f r$. Fernando Villaseñor, El libro iluminado en Castilla durante la segunda mitad del siglo XV, León, Fundación Instituto Castellano y Leonés de la Lengua, 2009, p. 136 n. 496. La presencia en la Biblia de D. Luis de Guzmán de dos talleres de miniaturistas ha sido estudiada por Sonia Fellous, La Biblia de Alba: de cómo rabi Mosé Arragel interpreta la Biblia para el gran maestre de Calatrava: Toledo 1422-1433, Paris, Somogy éditions d'art, 2001, pp. 116-123, señalando la participación de maestros y aprendices en una misma imagen y el caracter grosero y descuidado de algunas de las miniaturas (p. 120).

${ }^{8}$ Para una descripción de estos volúmenes con bibliografía actualizada $c f r$. Gemma Avenoza, Biblias 
La belleza material sitúa a estos manuscritos con pleno derecho dentro de la historia de la miniatura castellana medieval y por ello han sido objeto de la atención de los especialistas, que han identificado a alguno de los artistas que intervinieron en su iluminación. De la mano de Juan de Carrión, miniaturista activo en Segovia entre 1454 y 1470, surgieron las miniaturas de Esc. I-I-4, probablemente con la colaboración de algunos miembros de su círculo ${ }^{9}$ y existen indicios para relacionar parte de las miniaturas de la Biblia de Arragel con el llamado Maestro de los cipreses que trabajó en Esc. I-I-3, a quien se sugiere identificar con el miniaturista activo en Sevilla Nicolás Gómez ${ }^{10}$.

Estos estudios sitúan en un ambiente concreto a los manuscritos, se centran en los elementos plásticos y las formas preferidas por los artistas, se enfocan hacia su identificación y el entorno en el que trabajaron, pero no abordan de forma específica el programa iconográfico de los códices, no se detienen a reflexionar en el porqué de la aparición de determinadas imágenes en detrimento de otras (las historias de Dina y Balaam en Esc. I-I-4 ${ }^{11}$; la ilustración reducida al Génesis en Esc. I-I-7); en la disposición de la imagen (la historia de Job en Esc. I-I-5) o en las razones de la forma y disposición de las miniaturas en la página (las diversas series de Esc. I-I-4), por poner algunos ejemplos.

castellanas medievales, Logroño, Cilengua, 2011, pp. 53-78, 91-130, 199-253, 360, 362, 369, 378-380, 402-403, 406-409; José Luis Gonzalo Sánchez Molero, «Informe sobre la heráldica del Ms. Esc. I-I-4» en G. Avenoza, ibíd., pp. 421-424 pone al día la información sobre el escudo del Esc. I-I-4. Para las relaciones entre estos textos y nuevos puntos de vista sobre las fases de composición de Esc. I-I-4 véase F. Javier Pueyo Mena y Andrés Enrique-Arias, «Los romanceamientos castellanos de la Biblia Hebrea compuestos en la Edad Media: manuscritos y traducciones», Sefarad, 73:1 (2013), pp. 165-224. Complétese la bibliografía a través del enlace: $<\mathrm{http}$ //www.bibliamedieval.es/index.php/recursos/recursos-biblio $>$ [Consulta: 1/03/2016]. Para una relación de miniaturas y temas tratados en los códices escurialenses $c f r$. Julián Zarco Cuevas, Catálogo de los manuscritos castellanos de la Real Biblioteca de El Escorial, San Lorenzo de El Escorial, Imprenta del Real Monasterio, 1929, vol. 3, pp. 410-499, para las del ms. Esc. I-I-4 p. 440.

${ }^{9}$ Ana Domínguez, «Sobre Juan de Carrión y su círculo. Un documento de pago en la Catedral de Segovia y nuevas atribuciones», en Goya, 274 (2000), pp. 17-26, fue la primera en señalar a Juan de Carrión como el miniaturista de Esc. I-I-4, pero fue Villaseñor, ob. cit., quien ha profundizado más en la personalidad y las obras debidas a este y otros iluminadores activos en el reino de Castilla. Según Villaseñor la identificación de artistas se puede hacer gracias a la comparación de elementos comunes entre Esc. I-I-4 y el manuscrito del Libro del caballero Zifar hoy Paris, Bibliothèque Nationale, esp. 36 (pp. 136-137).

${ }^{10}$ Ana Domínguez, «Dos Biblias iluminadas en Toledo en torno a 1420: la Biblia de Alba y la Biblia Romanceada escurialense (Escorial, ms. I.J.3)», en Flanders in a European Perspective. Manuscript Illumination around 1400 in Flanders and Abroad, Proceedings of the International Colloquium, Leuven, 7-10 September 1993, Leuven, Peeters, 1995, pp. 473-485. Villaseñor, ob. cit., pp. 135-137.

${ }^{11}$ Sirva de ejemplo que Ana Domínguez Rodríguez no llegue a identificar el tema de la miniatura del f. 16v, la historia de Dina en su «Sobre Juan de Carrión», art. cit., p. 21, cuando ya la había identificado Julián Zarco Cuevas, ob. cit., vol. 3, p. 440. 
Nada de eso es casual, intentaremos comprenderlo teniendo en cuenta la naturaleza de las obras, los intereses del patrón, la condición y bagaje de los miniaturistas y los modelos de los que disponían.

\section{Biblia de Mosé Arragel. Madrid: Casa de Alba}

La Biblia de Arragel, encargo de D. Luis de Guzmán, Gran Maestre de Calatrava, es un ejemplo extraordinario de articulación de texto e imagen. Es una traducción glosada, obra de Mosé Arragel de Guadalajara realizada entre 1420 y 1431, que ilustran más de 320 miniaturas distribuidas de forma no homogénea en el volumen, puesto que hay libros que carecen de toda ilustración (Salmos, Zacarías, Lamentaciones, Cantar de los Cantares, Eclesiastés, Proverbios, y Crónicas), mientras que otros desbordan de imágenes (Génesis, Éxodo, Jueces, Samuel, entre otros) ${ }^{12}$.

Gracias a los paratextos de la Biblia de Arragel y al peculiar modo de redacción del comentario del rabino, podemos acceder a las relaciones establecidas entre la práctica totalidad de los actores implicados en el proceso de traducción y glosa, su copia, su ilustración y las distintas fases de escrutinio a las que fue sometida por los colaboradores cristianos de Mosé Arragel. Mediante la lectura de los textos preliminares y la observación de la disposición y contenido de texto, glosa e ilustraciones -siempre yuxtapuestos- se pone en evidencia el diálogo tejido entre todos ellos, la orientación explicitada en la glosa, las opiniones de Arragel no siempre evidentes en el comentario y las que corresponderían a las aportaciones de los colaboradores cristianos.

Mosé Arragel tiene muy claro que el destinatario de su trabajo es el Maestre de Calatrava Don Luis de Guzmán y a él se dirige en las glosas. En este discurso el rabino de Guadalajara se refiere a D. Luis como alguien a quien se leerá el libro y escuchará la historia y le sugiere que se haga «leer»o «mostrar» lo que dice el libro en otro punto. Este particular, que puede pasar desapercibido, es fundamental si tenemos en cuenta la importancia que tiene la ilustración en la concepción de esta Biblia ${ }^{13}$.

E aquí agora non de todo punto determinamos esta quistión, e sy más perfecta, señor Maestre, tu oyr e veer la quisieres, manda que te lean aqueste dicho paso en el Josué (Lev 9:24 glosa f. 94va) ${ }^{14}$

${ }^{12}$ Véase Sonia Fellous, ob. cit., pp. 116-117.

${ }^{13}$ Sobre los elementos midrásicos presentes en las miniaturas es fundamental Carl-Otto Nordström, The Duke of Alba's Castilian Bible. A Study of the Rabbinical Features of the Miniatures, Uppsala, Almqvist \& Wiksells, 1967.

${ }^{14}$ Reproduzco los textos y empleo la numeración numérico-alfabética de las glosas de la edición de The 
En este punto Arragel remite al Maestre a un extenso comentario copiado en el f. 172ra-va, con una ilustración de la batalla en el centro, de forma que vea la imagen y escuche la lectura.

A lo largo de la obra el glosador se dirige a su público con deícticos genéricos, que apuntan hacia la oralidad en la transmisión (un público que escucha a un lector), por ejemplo: «que adelante oiredes que al tal Josef fizo» (Gé 10:1 f. $33 v a)$. Es evidente que Mosé Arragel da por hecho que las más de las veces D. Luis no leerá por sí mismo el texto: «e d'esta puridat de los perlados e prestes en muchos logares oyste, señor Maestre, e oyrás, a Dios plaziendo» (Lev 23:25 f. 123vb). En otro pasaje Arragel invita a su lector a mirar la miniatura del folio anterior, ahorrándose así describir los estragos causados por el vino en Noé: «buelve la foja e verás don Noé qual está» (Gé 9:24 f. 33va).

Arragel, pese a las reservas iniciales acaba por emplear las miniaturas como un elemento más al servicio de la comprensión del texto y del comentario y es así como la yuxtaposición constante de texto, particular glosado e imagen se convierte en una exigencia de tal nivel que llega a obligar a un cambio de orden de las glosas marginales. Veamos un ejemplo: el sacrificio de Isaac (Gé 22). Esta historia es fundamental dentro del Antiguo Testamento porque representa el pacto de Dios con el pueblo elegido, que no volverá a destruir, antes consentirá que se multiplique infinitamente a cambio de una fe y una obediencia absoluta a sus designios.

En la Biblia de D. Luis de Guzmán este tema ofrece un ejemplo paradigmático de relación entre la miniatura y el comentario, que no sigue el orden del texto bíblico como es habitual en la obra, sino que Arragel anticipa al margen el f. 39vb las glosas que aluden directamente al contenido a la imagen, dejando para los márgenes del folio siguiente las glosas de versículos anteriores. Este es un caso extremo de vínculo entre una miniatura y el comentario con el que está relacionada, porque en este punto la figura no ilustra exactamente el texto bíblico (si así fuera, la miniatura estaría situada en la parte superior de la columna, y no en la inferior), pero tampoco se corresponden todos sus elementos con la glosa a la que acompaña.

El orden de las glosas y su posición es el que sigue (subrayamos las que están junto a la miniatura): 39va [22:1, continuada en 39vb]; 39vb [22:2a, 22:9, $\underline{22: 6 \mathrm{a}}, \underline{22: 4 \mathrm{~b}}, \underline{22: 11}, \underline{22: 12 \mathrm{a} \text { y } 22: 12 \mathrm{~b}}$, continuada en 40ra] y 40ra [22:13, 22:16, $22: 2 \mathrm{~b}, 22: 4 \mathrm{a}$ y $22: 4 \mathrm{c}$, continuada en $40 \mathrm{rb}$ ], 40rb [22:5, 22:6b, 22:15 y 22:20].

Old Spanish Bible of Moshe Arragel. Vol. 1: Introduction and Prologue, vol. 2: Genesis, ed. de Luis GirónNegrón, Andrés Enrique-Arias, Francisco J. Pueyo Mena y Ángel Sáenz-Badillos †, Leiden, Brill, 2017, obra en preparación, a la que he podido acceder por cortesía de sus autores, juntamente a sus concordancias. 


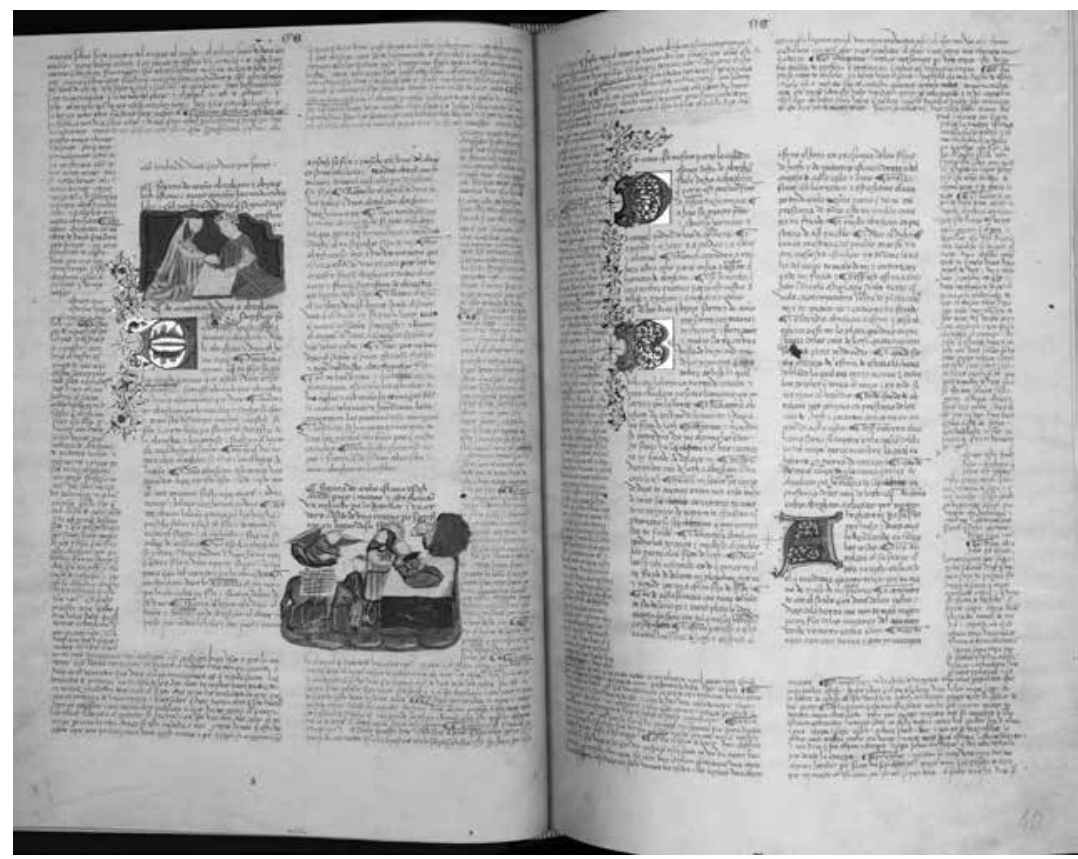

[2] Madrid, ADA, ms. Vitrina ff. 39v-40r (C) Casa de Alba

La imagen superpone varias escenas y se lee de izquierda a derecha, al modo cristiano ${ }^{15}$. En el margen inferior izquierdo, en primer plano el asno con la leña al lomo mira hacia la yerba del suelo que está comiendo [22:4c f. $40 \mathrm{rb}$ y $22: 6 \mathrm{a}^{16}$ f. 39vb]; tras él los dos mozos de Abraham miran en dirección opuesta al altar [22:4c f. 40ra-rb]; en el ángulo superior izquierdo el ángel surge de una nube deteniendo a Abraham $\left[\underline{22: 4 b}^{17}\right.$ y $\underline{22: 11}^{18}$ f. 39vb]. En la parte derecha vemos el altar sobre el que está Isaac con las manos atadas mientras su padre le sujeta y pone el cuchillo en su cuello $\left[{\underline{22: 6 b^{19}}}^{19}\right.$ f. $\left.39 \mathrm{vb}\right]$.

${ }^{15}$ Siguen a cada escena las glosas que le corresponen y su posición, subrayando las que la flanquean.

$\left.{ }^{16} 22: 6 a\right]^{*}$ E cortó Abraham la leña que tenía para la holocasta, e púsola sobre Isaque, su fijo, etc. Abraham maginó que quiçab allí donde le mandavan sacreficar su fijo que non avería leña para fazer la holocasta. Otros dizen que, por cuanto la leña, que cría gusanos, que es cierto que non podían quemar los sacreficios con ella. Abraham, pues fallava leña bastante que non criava gusanos, por tanto la levó desde acá. The Old Spanish Bible of Moshe Arragel, ob. cit.

$\left.{ }^{17} 22: 4 \mathrm{~b}\right]^{*}$ E vío el lugar de lexos, etc. Parece que conoció el lugar en que estava una nuve en somo d'él. The Old Spanish Bible of Moshe Arragel, ob. cit.

$\left.{ }^{18} 22: 11\right]^{*}$ E llamólo el ángel de Dios desde los cielos, etc. Cuando a Abraham alguna cosa Dios le quería dezir, el ángel mesmo le embiava acá a le dezir las cosas en la tierra. $\mathbf{E}$ aquí, para le dezir que non degollase su fijo, dize que lo llamó el ángel de Dios desde los cielos. Fue así la razón: que ovo recelo que en tanto qu'él descendía acá, que lo degollaría, e por tanto lo ovo de llamar e ge lo dezir desde los cielos. The Old Spanish Bible of Moshe Arragel, ob. cit.

$\left.{ }^{19} 22: 6 \mathrm{~b}\right]^{*}$ E fuéronse ambos de consuno. En yendo, vino el Satán e parósele a la man diestra de Isac, e díxole así: — ¡Oh cuitado, fijo de la cuitada! ¡Cuántos ayunos malos ayunó tu madre ante que te oviese, 
Abraham es sorprendido por la voz del ángel, hacia el que gira el rostro y no consuma el sacrificio [22:12 $\mathrm{a}^{20}$ f. $39 \mathrm{vb}$ ]. Por último, en el ángulo superior derecho vemos un arbusto del que asoma un carnero que substituirá al niño en el sacrificio [22:13 f. 40ra].

Esta escena no concuerda en todos sus detalles con los textos que ilustra. La leña que corta Abraham no se puso a lomos del asno, sino que la cargó Isaac tal y como recoge la traducción bíblica de Arragel, aunque no la glosa ${ }^{21}$, que se centra en la calidad de leña necesaria para el holocausto (22:6a). La nube que señala el lugar del sacrificio no pudo ser vista por los mozos; de ella asoma el ángel (voz de Dios, que no Dios mismo), tal y como se explica detalladamente en las glosas contiguas (22:4b y 22:11). La glosa siguiente (22:6b) explica el porqué Isaac aparece con las manos atadas y los ojos vendados, elemento que a simple vista implicaría el rechazo del joven a la voluntad de Dios. También se explica en este punto que al oír al ángel, el cuchillo cayó de la mano de Abraham y entonces intentó matar a Isaac con sus manos.

Las glosas desplazadas de su lugar natural complementan (y hasta cierto punto incluso corrigen) lo que muestra la imagen ${ }^{22}$, explicando acciones que no se han podido representar o que no explicita el texto bíblico. Por lo tanto, este es un ejemplo paradigmático en el que texto, glosa y miniatura componen en su conjunto un discurso complejo y complementario del que se podrá aprovechar quien escuche el texto y vea la imagen.

De este modo se cumple con el deseo del patrón de una traducción nueva, ilustrada con una glosa en la que se fundiera la exégesis cristiana con las más

e aún este viejo tu padre! ¡E agora áse enloquecido, que te va a degollar! Isac dixo a su padre: - Señor, verás qué me dize aqueste. Dixo el padre: -Fijo, non cures d'él, que lo dize por te pavor poner. Fuéronse ambos dos. Dixo Isac: «Señor, átame bien pies e manos por que non refuse la muerte». Estonce atara a Isaque su padre, e tomó Abraham el cuchillo para degollar a su fijo. Dixo al padre: «Señor, non fagas esto saber a mi madre estando en lugar peligroso así como en boca de algún pozo o de algún texado». The Old Spanish Bible of Moshe Arragel, ob. cit.

${ }^{20}$ 22:12a] E dixo: «non tiendas tu mano al moço». Cuando tornó, fallóse sin cuchiello Abraham. Dixo Abram: «parece que este moço non es bastante de ser fecho d'él tan grande sacreficio e virtuoso». Como éste quísolo afogar, óvole de dezir el ángel: «nin le fagas cosa alguna». The Old Spanish Bible of Moshe Arragel, ob. cit.

${ }^{21}$ Isaac cargando la leña está representado en Esc. I-I-3 f. 13r, donde la imagen se lee de derecha a izquierda, a la hebrea.

${ }^{22}$ Nótese que Arragel en las glosas llega a discrepar abiertamente de lo representado en las miniaturas, p. e. Sa1 15:27, donde la miniatura va acompañada del título: «Cómo Samuel la ropa a Saul ronpió en signa que el regno de él ronpían e a David lo davan». f. 203rb 15:27] E asiole de la falda del su manto e ronpiós. Los glosadores son aquí divisos, que non determinan quién ronpió a quién la falda, o Samuel a Saul o Saul a Samuel, non enbargante que el ystoriador que aquí la ystoria ystorió e pintó, pintó a Samuel que él ronpía la falda a Saul, qualquier d'ellas pueden estar. Pero a lo público más me paresçe que se podrá sostener Saul al Samuel, que non la contra, por quanto el testo testimonia que Samuel se yva ya después de su reprehenssión y revelaçión fecha. The Old Spanish Bible of Moshe Arragel, ob. cit. 
autorizadas y actualizadas opiniones de la exégesis judía, destinadas a facilitar una mejor comprensión del texto.

\section{Esc. I-I-4}

El programa iconográfico inicial de Esc. I-I-4 se reducía a los frontispicios de Gé (f. 1r) e Is (f. 340r) -correspondientes a los inicios de la biblia en dos volúmenes que estaba reproduciendo-, a unas iniciales de libro de gran belleza en las que no se escatimaron el oro ni los colores delicados, unas iniciales secundarias elaboradas en rojo y azul con decoración filiforme en el color complementario y a la ejecución de las rúbricas en tinta roja ${ }^{23}$.

El copista no dejó espacios para ilustraciones, por lo que cuando se decidió enriquecer el volumen con miniaturas, éstas se ubicaron en los márgenes inferiores de los folios ${ }^{24}$. Se trata, por lo tanto, de la misma situación que hemos examinado en el manuscrito de las Ceremonias de San Millán.

Al códice acabado se añadieron tres series de imágenes: el sacrificio de Isaac (Gé 22), la historia de Dina hija de Jacob (Gé 34), y otra que Zarco Cuevas entendió como representación de dos motivos, por una parte la embajada de Israel al rey de los Amorreos y, por otra, la aparición de un ángel a Moisés, pero que en realidad corresponden a la historia de Balaam (Nú 22-24) ${ }^{25}$.

En los folios 9v y 10r tres miniaturas cuadradas reproducen escenas del sacrificio de Isaac: Abraham recibe la orden de Dios; el camino hacia el lugar del sacrificio y la aparición del ángel que salva a Isaac. El ciclo de Abraham y muy especialmente la escena del sacrificio de Isaac es frecuente en las ilustraciones de las biblias, mientras que la de Abraham en oración recibiendo la orden divina lo es menos ${ }^{26}$.

\footnotetext{
${ }^{23}$ Para una explicación sobre la hipótesis de Esc. I-I-4 como copia de una biblia en dos volúmenes y muestras de la decoración del códice, vid. Avenoza, ob. cit., pp. 69-71.

${ }^{24}$ Existen delicadas biblias historiadas, como la traducción de Jean de Sy, Paris, Bibliothèque Nationale, fr. 15397, en las que además de las ilustraciones incluidas en el cuerpo del texto, en los márgenes inferiores se comenzó a realizar otras miniaturas, algunas con los dibujos inacabados (p. e. ff. 29r-30v) y otras, como la que recoge el tema del sacrificio de Isaac completas (f. 35v), cfr. Gallica. Enlace: <http:// gallica.bnf.fr/ark:/12148/btv1b84471814> [Consulta: 1/3/2016].

${ }^{25}$ Véase la relación de miniaturas y temas tratados en los códices escurialenses en Zarco Cuevas, $o b$. cit., vol. 3, p. 440.

${ }^{26}$ Cfr. Louis Reau, Iconografia del arte cristiano, Barcelona, Ediciones del Serval, 1999-2002, 2a ed., vol. 1, pp. 165-168. Gaston Duchet-Suchaux y Michel Pastoureau, Guía iconográfica de la Biblia y los santos, Madrid, Alianza Editorial, 2009, pp. 12-14.
} 


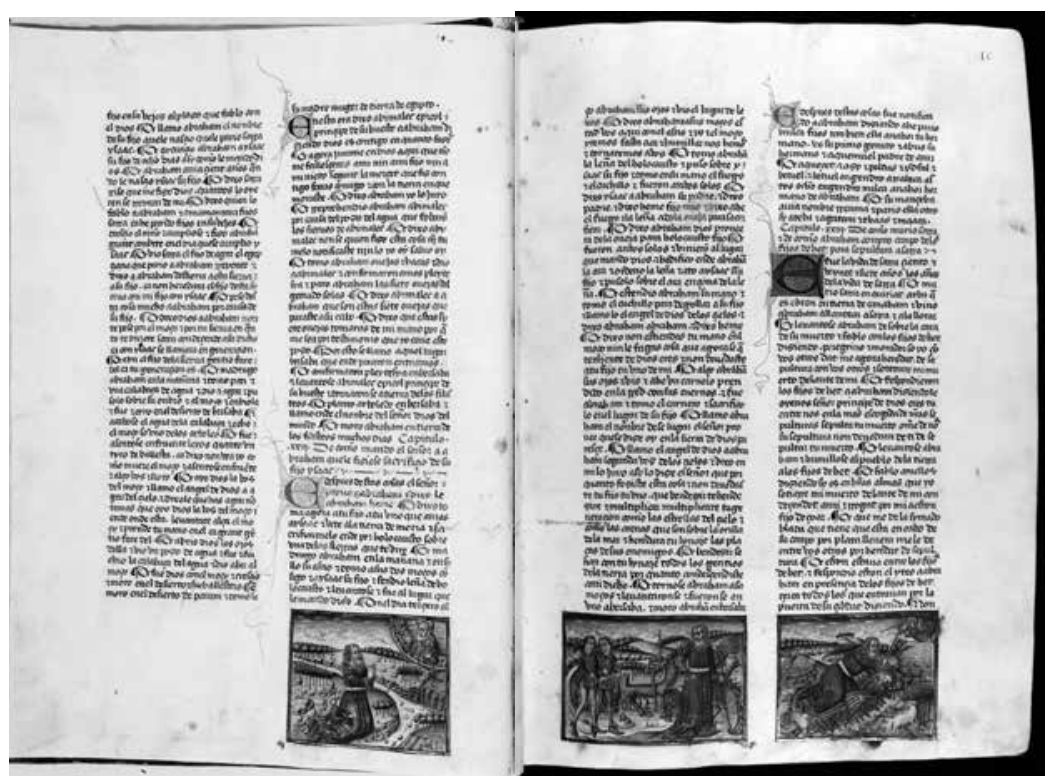

[3a y 3b] Esc. I-I-4 ff. 9v-10r (C) Patrimonio Nacional

Ocupando toda la parte inferior del f. 16v en un rectángulo se reproducen tres episodios de la historia de Dina, hija de Jacob y Lía, que aunque tienen características de estilo y cromatismo diferentes de los anteriores también proceden del círculo de Carrión ${ }^{27}$. En estas ilustraciones todos los personajes visten «a la moderna», reproduciendo atuendos y usos cortesanos contemporáneos, mientras que en la serie anterior sólo Isaac y los criados visten de esa forma, y los ropajes de Abraham son los habituales de un patriarca, como es habitual en el arte medieval y renacentista cuando se representa a los personajes del antiguo y del nuevo testamento. La imagen se lee de izquierda a derecha: se inicia mostrando a Dina paseando junto a las mujeres de la tierra, continúa con el rapto de Dina por Siquem a quien se representa junto a una ciudad, vestido según su condición principesca y acompañado por su ejército (lo que introduce un componente de fuerza en la acción) ${ }^{28}$. La narración iconográfica se cierra con una escena triple que muestra cómo Jamor (padre de Siquem) y su pueblo se circuncidan a petición de los hijos de Jacob para consentir las bodas entre Dina y Siquem, la debilidad les hace guardar cama y, por último, Simón y Leví entran en la ciudad matando a todos los varones

${ }^{27}$ Ana Domínguez, «Sobre Juan de Carrión», p. 21. Villaseñor, ob. cit., p. 136.

${ }^{28}$ Las formas arquitectónicas y la disposición de los hombres de armas son parte de los elementos que permitieron identificar al autor de esta miniatura con Juan de Carrión, dada su semejanza con miniaturas del Zifar, cfr. Villaseñor, ob. cit., pp. 136-137. 
para vengar a su hermana ${ }^{29}$. Pese a la buena voluntad de Siquem y de su padre, pese a las ofertas de paz, los hermanos de Dina no pueden pasar por alto el ultraje hecho a su hermana, puesto que un hombre no circuncidado la ha forzado, lo que se entiende como una inadmisible relación sexual interreligiosa ${ }^{30}$. En la época en la que se compuso este manuscrito la sociedad hispánica también prohibía de forma taxativa las relaciones sexuales entre personas de diferente religión (pueblos circuncidados y no circuncidados en el pasaje bíblico). Y los castigos para aquel cristiano que yaciera con judía o para judío que yaciera con cristiana eran graves ${ }^{31}$.

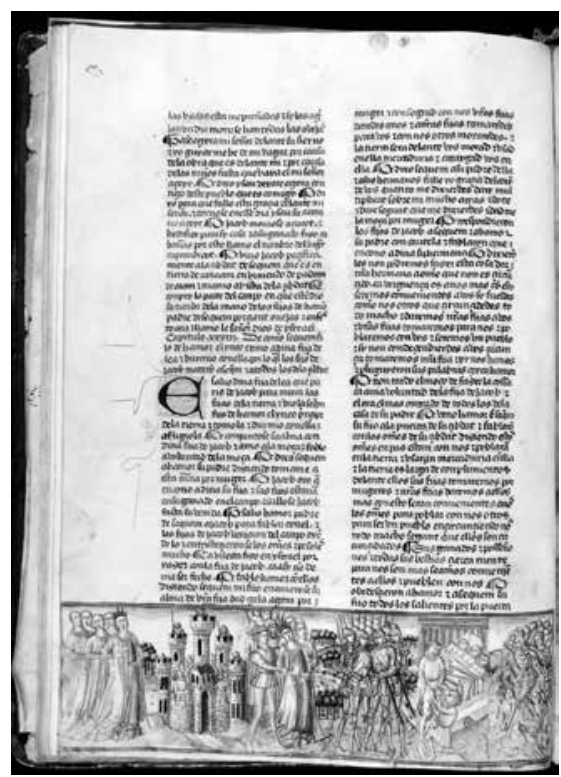

[4] Esc. I-I-4 f. 16v (C) Patrimonio Nacional

Dina es un tema infrecuente en la iconografía, por eso la representación de su infortunio y el protagonismo que tiene en ella la figura de la muchacha, desconcierta un tanto. ¿Fue una excusa para representar un grupo de damas, un encuentro galante, un ejército y una matanza en una sola escena, combinando distintos temas solicitados por el patrón?

Esta historia no aparece en las biblias medievales iluminadas. Solo la venganza de Leví y Simón se encuentra en una de las biblias castellanas: en la de Mosé Arragel. La imagen del estupro no sedujo al rabino de Guadalajara, quien sí dispuso que se ilustrara cómo Simón y Leví mataban a los siquemitas, bajo la leyenda: «Figura de

\footnotetext{
${ }^{29}$ Reau, ob. cit., vol. 1, p. 185 menciona solo tres ejemplos del episodio (s. v, Roma: Mosaico de Santa María la Mayor -con varias escenas del episodio, pero en ninguna de ellas aparece Dina-; s. xvI: una pintura de 1531 y un tapiz). Duchet-Suchaux y Pastoureau, ob. cit., pp. 172-174 no mencionan la historia de Dina como parte del ciclo inconográfico de Jacob.

${ }^{30}$ La prohibición de los matrimonios mixtos procede del Deuteronomio 7:3 y los peligros que entrañan se recuerdan en $\mathrm{Ne}$ 13: 23-25. En ese mismo capítulo ( $\mathrm{Ne} 13: 2$ ) se menciona a Balaam, quien fue requerido por los amonitas y moabitas para maldecir al pueblo de Israel, justo al inicio de la explicación de a qué pueblos se debe considerar extranjeros y a cuales no.

${ }^{31}$ Cfr. José Hinojosa de Montalvo, «La inserció de la minoria hebrea en la formació social valenciana», Revista d'Història Medieval, 4 (1993), pp. 45-65, esp. las pp. 51-55 dedicadas a la prostitución y su persecución y Yom Tov Assis, «El comportament sexual en la societat hispanojueva de l'edat mitjana», Tamid, 3 (2000-2001), pp. 7-47, trad. de «Sexual behaviour in mediaeval Hispano-Jewish society», en Jewish history. Essays in Honour of Chimen Abramsky, ed. de A. Rapoport-Albert y S. J. Zipperstein, Londres, Peter Halban, 1988, pp. 25-59.
} 
Simón e Leví con sus espadas» (f. 47vb) ${ }^{32}$. En la glosa, en cambio, Mosé Arragel comentó ampliamente el episodio de la salida de Dina como muestra de mala costumbre femenina de consecuencias fatales:

E salló Dina fija de Lea. También era fija de Jacob e aplicola aquí a Lea, que tanto quería dezir que era sallidera [f. 47va] fija de otra sallidera. Sallidera fue Lea que bien sabes que salló a trabar de Jacob que durmiesse con ella, pues lo tenía esa noche conprado por las mandrágolas de su fijo Rubén. E agora la fija suya porque salló a mirar a las mugeres de la tierra la tomó Sachem. Nota que la muger e la gallina por sallyr de casa se pierden, e ençerradas onestamente estar deven. (ADA Vitrina Biblia f. 47rb-va glosa)

Arragel continúa en la glosa siguiente argumentando sobre el significado de «yugó con ella e afrigiola», basándose en Rabí Salomón (Salomón Rashí) y Rabí Abraham (Abraham Abulafía) ${ }^{33}$.

El hecho de que no se representara a Dina no quiere decir que su historia fuera poco conocida. Las leyendas en torno a esta muchacha eran complejas y con abundantes derivaciones que glosaban desde su juventud cuando sucedieron los hechos, las razones por las que salió al encuentro de las mujeres siquemitas, la relación entre su desgracia y la condición poco recatada de su propia madre (refiriéndose al episodio de Rubén y las mandrágoras que facilitó su engendramiento Gé 30:14-15), la ocultación de Dina por Jacob cuando fue al encuentro de su hermano Esaú (un incircunciso) temiendo que quisiera desposarla (tema no mencionado en la biblia), sus maridos (su hermano Simón y, en especial, la identificación entre Dina y la segunda esposa de Job que también era un incircunciso ${ }^{34}$ ). Recordemos que la mujer de Job incitada por el diablo le pidió que renegara de Dios, puesto que tanto le maltrataba, y esas palabras son paradigma del mal consejo de una esposa ${ }^{35}$.

Según Josefo, Dina salió de casa un día en el que los siquemitas celebraban una gran fiesta ${ }^{36}$, pero según las leyendas judías, esto sucedió mientras su padre y sus hermanos permanecían en la casa de oración estudiando la Tora; entonces Dina salió a la calle para ver a las mujeres que cantaban y bailaban,

\footnotetext{
${ }^{32}$ Vid. infra la relación de Mosé Arragel con la dirección de los miniaturistas de esa biblia.

${ }^{33}$ Tomo esta información sobre las autoridades rabínicas mencionadas por Arragel de The Old Spanish Bible, ob. cit.

${ }^{34}$ Cfr. Louis Ginzberg, The Legends of the Jews, Philadelphia, The Jewish Publication Society of America, vol. 1, 1961, pp. 395-400; vol. 2. 1964, pp. 10, 27, 37, 38, 76, 84, 93, 114, 139, 142, 225, 241; vol. 5, 1955, pp. 313, 314, 319, 336, 366, 375, 382, 388.

${ }^{35}$ Arragel, glosa a Jb 2:9-10: «que las mugeres son causa en fazer pecar a sus maridos, e que los maridos non las deven creer, mas habuminar sus judizimientos, según que fizo Job con su muger» f. 427vb.

${ }^{36}$ Josephus, Jewish Antiquities, ed. y trans. de H. St. J. Thackeray, London, Harvard Univeristy Press, [1930] 1998, book I, § 337-340.
} 
incitadas a ello por Siquem para conseguir que Dina saliera de casa. «Had she remained at home, nothing would have happened to her. But she was a woman, and all women like to show themselves in the street» ${ }^{37}$. La General estoria recoge la historia de Dina a partir del relato de Josefo, pero desplaza la culpa a la concupiscencia de Siquem, tal como se desprende de la respuesta de Simón y Leví a Jacob, cuando éste les recrimina por la matanza y el saqueo de la ciudad:

— ¿Cómo, pues assí avién ellos a fazer de nuestra hermana como de mugier refez, e tenérnosla forçada, e que nos non vengássemos d'ello? ${ }^{38}$

La leyenda judía, por su parte, cuenta que lo que le sucedió a Dina fue un castigo divino por la negativa de Jacob a darla por esposa a su hermano Esaú:

therefore Dinah will have to marry Job, one that is neither circumcised nor a proselyte. Thou didst refuse to give her to one that is circumcised, and one that is uncircumcised will take her. Thou didst refuse to give her to Esau in lawful wedlock, and now she will fall a victim to the ravisher's illicit passion ${ }^{39}$.

La siguiente imagen que encontramos en Esc. I-I-4 es de un estilo semejante, pero de peor ejecución y está en un estado lamentable de conservación ${ }^{40}$, y da la impresión de que ha sido deteriorada de forma voluntaria ${ }^{41}$. Ocupa la franja inferior del f. 76v y está dividida en tres escenas: la primera representa al rey Baloc, hijo de Sifor, que ordena a tres jóvenes que partan en busca de Balaam para que maldiga a los judíos; en el centro esos tres mensajeros recorren el campo a caballo y en la tercera escena se presentan ante Balaam tras el cual está el ángel como representación de Dios (Nú 22:1-20). Esta historia tienen su continuación al pie del f. 77r, en una miniatura de la que sólo se conserva un boceto incompleto, que representa cómo Balaam golpea a su asna (que gira la cabeza hacia él como si le hablara) cuando el ángel le impide avanzar (Nú 22: 21-22). En este punto también se cumple la

${ }^{37}$ Cfr. Ginzberg, ob. cit., vol. I, p. 395.

${ }^{38}$ Alfonso X el Sabio, General estoria. Primera parte, coord. por Pedro Sánchez-Prieto Borja, Madrid, Biblioteca Castro, vol. 1, p. 371.

${ }^{39}$ Ginzberg, ob. cit., vol. I, p. 396.

${ }^{40}$ Villaseñor, ob. cit., p. 136 menciona la imagen pero no la comenta, aduciendo su poco interés y carácter inacabado.

${ }^{41}$ No sería la primera ocasión en la que un texto (en este caso una imagen), percibida como deshonesta se intenta eliminar borrándola, $c f r$. el poema conservado en La Seu d'Urgell estudiado en G. Avenoza, «Decidle al caballero. Una nueva versión de un villancico del Cancionero de Uppsala», en Studi di Filologia romanca offerti a Valeria Bertolucci Pizzorusso, ed. de P. G. Beltrami et al., Pisa, Pacini ed., 2006, vol. 1, pp. 91-105. 
condición de proximidad entre el texto y la imagen que lo ilustra: «E levantose Balam en la mañana e ensylló su asna e fuese con los cavalleros de Moab» (Esc. I-I-4 f. 77ra-rb).

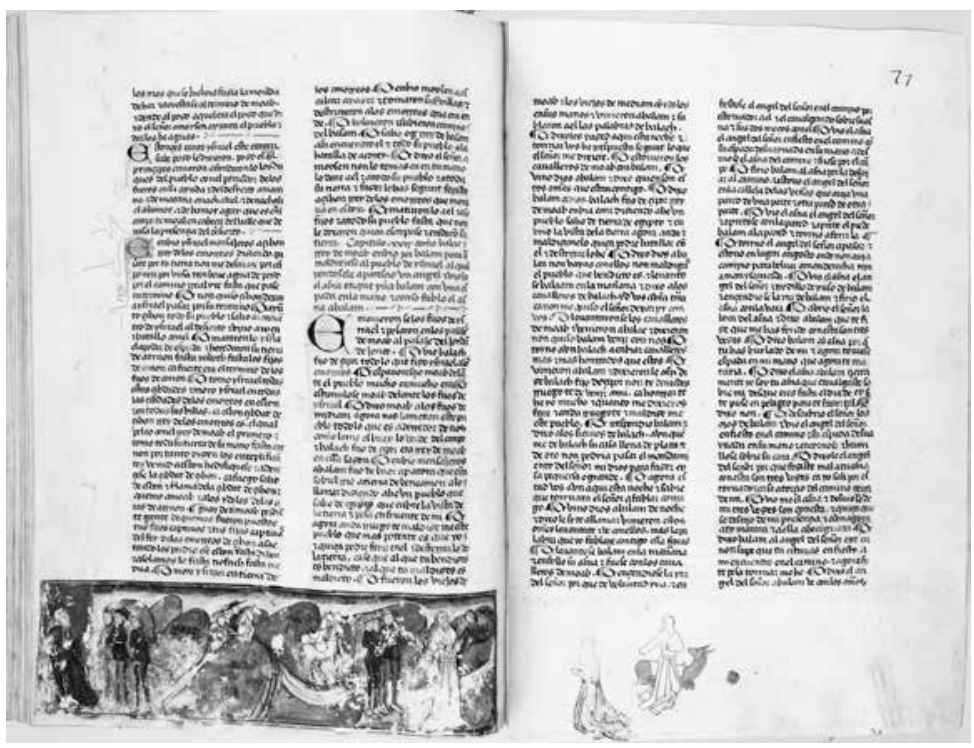

[5a y 5b] Esc. I-I-4 ff. 76v-77r (C Patrimonio Nacional

La imagen de Balaam, su asna y el ángel es frecuente en la iconografía religiosa medieval cristiana, puesto que se interpretaba como prefiguración de la aparición de Jesucristo a Tomás de Aquino, menudeando sus representaciones ${ }^{42}$. En algunas imágenes también aparece la profecía de la estrella de Jacob, entendida como anuncio del nacimiento del Mesías, pero no hemos visto mencionada ninguna representación de la historia de Balaam que incluya al rey de Moab y sus mensajeros, tal y como aparece en Esc. I-I-4 ${ }^{43}$. La historia de Balaam y su asna se ha difundido ampliamente en el folklore popular, interpretando las palabras del animal como referencia a una relación carnal: «¿No soy yo tu asna, la que has montado desde que existes hasta hoy?» (Nú 22:30). Este episodio tiene amplios desarrollos en las leyendas hebreas, en las que se muestra cómo el asna escarneció a Balaam ante los enviados de Balac denunciando su deshonesta conducta ${ }^{44}$. Estos matices no se plasmaron en la General estoria, pero tuvieron su espacio en la glosa de Mosé Arragel, quien llama a Balaam «enbaucador o mago» y dice que «era

\footnotetext{
${ }^{42}$ Tanto iconográficas como literarias, cfr. Alfonso X el Sabio, ob. cit., vol. 2, pp. 776-780.

${ }^{43}$ Reau, ob. cit., vol. 1, pp. 257-258. Duchet-Suchaus y Pastoreau, ob. cit., p. 54.

${ }^{44}$ Ginzberg, ob. cit., vol. III pp. 363-365.
} 
fechizero malvado luxurioso [...] que segund pone el texto adelant que se echava con la su misma asna en que andava» (f. 126rb), con lo que no queda duda alguna de cuál era la opinión que del personaje tenía el rabino de Guadalajara y probablemente también sus contemporáneos.

La ilustración de la historia de Balaam, el asna y el ángel, que en Esc. I-I4 no se llegó a completar, sí se incluyó en Esc. I-I-3 f. 96v. En la Biblia de Arragel, en cambio, este relato no está acompañado por imagen alguna, pero la glosa ofrece una extensísima explicación sobre el episodio que ocupa los márgenes de los ff. 125vb-127ra.

Desconocemos las razones que llevaron a incluir estas ilustraciones correspondientes a pasajes del Génesis y no otras en Esc I-I-4. Su ubicación en el manuscrito no es aleatoria, sino que están situadas en una posición lo más cercana posible al pasaje que ilustran, como complemento visual y comentario gráfico al texto. Proceden de modelos radicalmente distintos (al menos un modelo para las del f. 10 y otro para las demás) y se trata de historias tras las cuales está o un momento clave de la historia de Israel (la primera) o una crítica de costumbres que se entendían como desviadas sumada a una dilatada discusión exegética (el resto), tal y como lo demuestra la glosa que Mosé Arragel incluye en su obra y que sustituye a toda imagen ${ }^{45}$.

\section{Esc. I-I-7}

El manuscrito Esc. I-I-7 es un códice magnífico en pergamino que fue mutilado privándole de las iniciales de libro, pero que por fortuna conserva cuatro de las miniaturas que adornaban el Génesis y el Éxodo ${ }^{46}$. Todas ellas corresponden a una misma tipología: miniaturas de columna situadas en el interior de la caja de escritura, enmarcadas por un triple marco (blanco, rosado y oro), finamente dibujadas y coloreadas. En el Génesis, acéfalo, se conservan dos miniaturas: la primera representa la actitud de los hijos de Noé ante la desnudez de su padre (f. 1va) (Gé 9: $24^{47}$ ) y la segunda las ciudades de Sodoma y Gomorra pasto de las llamas (f. 4vb). En los folios iniciales perdi-

\footnotetext{
${ }^{45}$ Nos parece demasiado arriesgado proponer que las series de Dina y Balaam se hayan incorporado al manuscrito por su carácter de reprehensión de conductas sexuales desviadas, tanto femeninas (Dina, que pone en riesgo su honor por su falta de recato), como masculinas (Balaam, que comete bestialismo con su asna).

${ }^{46}$ Recordemos que en Esc. I-I-4 las miniaturas solo aparecen en Génesis, mientras que en Esc. I-I-7 lo hacen en Génesis y Éxodo.

${ }^{47}$ El denominado "Escarnio de Noé" se interpretó como una prefiguración del escarnio de Cristo cuando le fueron arrebatadas las vestiduras, y por esa razón se incluyó frecuentemente en los ciclos iconográficos medievales pese a la procacidad de la escena, $c f r$. Reau, ob. cit., vol. 1, pp. 139-141; tema apenas tratado por Duchet-Suchaux y Pastoreau, ob. cit., p. 245.
} 
dos es más que probable que hubiera alguna otra imagen relativa a la creación del mundo, a la historia de Adán y Eva o al Diluvio.

Las dos miniaturas del Génesis están situadas justo tras el texto que ilustran:

E tomó Sem e Jafet la sávana e pusieron la sobre sus cuestas amos a dos. E andudieron contra tras e cubrieron las vergüenças de su padre, e sus rrostros contra tras e las vergüenças de su padre non vieron. (Gé 9:23, f. 1va)

E el Señor fizo llover sobre Sodoma e Gomorra sufre e fuego de Dios de parte de los çielos. (Gé 19:24, f. 4vb)

Y otro tanto sucede con las del ciclo de Moisés. En el f. 22va la necesaria contigüidad entre texto e imagen ha provocado que el espacio destinado a la miniatura fuera menor que el necesario según el modelo y que, por lo tanto, ésta haya ocupado parte del margen inferior: «aparesçió a él ángel del Señor en flama de fuego dentro en la çarça e vido que ardía la çarça en fuego e la çarça non se quemava» (Éx 3:2).

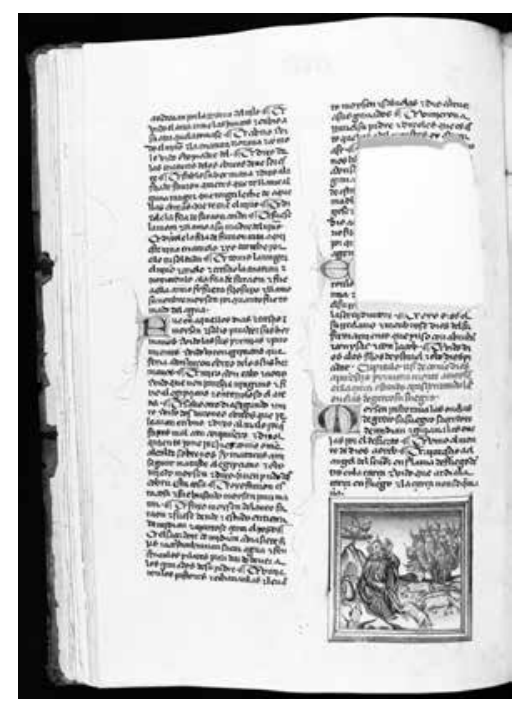

[6] Esc. I-I-7 f. 22v (C) Patrimonio Nacional

Un poco más adelante vemos como el copista ajusta los espacio destinados a las imágenes con el texto, de modo que la escena de la piedra que manó agua encaja perfectamente al final de la columna siguiendo al texto que ilustra (Éx 17:6 f. 30rb). 
Llama la atención y es difícilmente explicable que en Esc. I-I-4 las miniaturas decoren sólo el Génesis y Génesis y Éxodo en Esc. I-I-7. ¿Por qué acompañar con imágenes esos libros y no los demás? ¿Razones económicas? ¿Cambio de originales a reproducir? ¿Influencia de las tradiciones iconográficas? Sabemos que en los ambientes cristianos medievales existían modelos para toda la Biblia, pero en el judío éstos se reducían a las imágenes relativas al Génesis y al Éxodo que decoraban las Haggadot ${ }^{48}$. De hecho, todos estos manuscritos reproducen traducciones del texto hebreo al castellano, por lo que tal vez la selección de temas a ilustrar puede mantener también alguna relación con sus remotos modelos conceptuales para la iconografía, que no serían directamente bíblicos, sino que dependerían de los transmitidos por las Haggadot.

\section{Esc. I-I-5}

Esc. I-I-5 transmite la segunda parte del romanceamiento bíblico que se copia en Esc. I-I-7, pero que no forma con ese manuscrito una unidad codicológica ${ }^{49}$. Presenta un amplio programa iconográfico que incluye unos ricos frontispicios para los libros de Isaías y Jeremías e iniciales historiadas, de preciosa realización, para el resto de los libros. Además de esas imágenes, en el manuscrito hay una miniatura de columna en el f. $3 \mathrm{vb}$ y una serie de imágenes que ilustran la historia de Job en los ff. 166v-167r.

La miniatura del f. $3 \mathrm{vb}$ representa a Jesucristo sentado en un trono en majestad, rodeado de querubines. En una biblia destinada a cristianos realizada en ambientes donde podía ser sospechosa de criptojudaísmo, la presencia de esta imagen está perfectamente justificada. El texto de Is 6:1-3 describe la visión que el profeta tuvo de Dios, que los cristianos interpretan como un anuncio de la venida de Jesucristo, y como Jesucristo lo ha representado el miniaturista de Esc. I-I-5 y también lo hizo así el miniaturista de la Biblia de Arragel.

Este pasaje resultó complejo de glosar a Mosé Arragel, puesto que no era sencillo concordar las interpretaciones de unos y otros, así leemos en el f. 267r: «E a Dios plaziendo en syngular quaderno por ssy concordaremos estas

\footnotetext{
${ }^{48}$ «Mientras algunos ciclos bíblicos se limitan al Éxodo, otros son más extensos. La Haggadah de Sarajevo, la más completa, empieza con la creación del mundo prosigue hasta la muerte de Moisés y presenta también escenas de la vida de entonces». En la Haggadah de oro y en la Haggadah catalana se incluyen episodios del Génesis y del Éxodo y según Fellous, ob. cit., «La iconografía del ciclo bíblico se asemeja a la de los salterios y a la de las biblias latinas de Francia y de España. Pero la originalidad de las haggadot reside en el gran número de elementos midrásicos insertados en la narración bíblica» (pp. 62-63).

${ }^{49}$ Avenoza, Biblias, p. 111.
} 
prophecías [...] en el syngular quaderno de glosa apartada fallarás la concordança de las quatro o seys alas» cuando no es habitual que Mosé Arragel se refiera a materiales propios que no haya incluido en sus glosas. Por los preliminares de esta biblia sabemos que Fr. Arias Enzinas se comprometió a ayudar a Arragel «con sano e noble consejo» (f. 11vb) y proporcionarle un «registro» de las «opiniones de la fe romana» (f. 12ra), para que las añadiera a las de los exégetas judíos. Este es el único testimonio de que Arragel también proporcionara a Fr. Arias un cuaderno o registro independiente con explicaciones exegéticas judías, complementarias a las que incorporó a la glosa.

El siguiente grupo de miniaturas narrativas de Esc. I-I-5 ilustran la vida de Job (ff. 166v-167r).

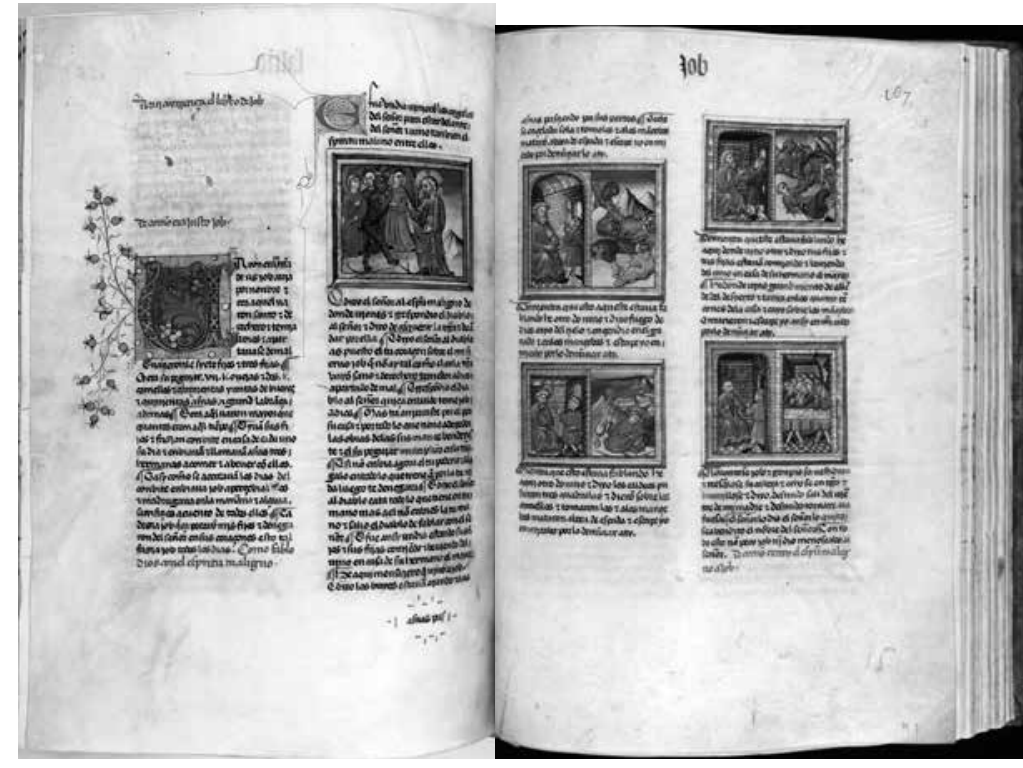

[7a y 7b] Esc. I-I-5 ff. 166vb-167rb @ Patrimonio Nacional

La posición texto / imagen sigue siendo la misma: primero el texto e inmediatamente después la imagen que lo ilustra. La primera de las miniaturas de este grupo en Esc. I-I-5 se refiere a Jb 1:6: «E fue un día vinieron los ángeles del Señor para estar delante el Señor e vino tanbién el diablo entre ellos».

Esta escena se encuentra también en la Biblia de Arragel, en el margen inferior del f. 427r, y sobre ella se lee el mismo texto. En este segundo manuscrito la imagen es mucho mayor que en el escurialense; coinciden en la representación de Dios como Cristo, pero en Arragel se le muestra en majestad, sentado en un estrado dentro de una mandorla con el orbe en la mano, entre dos grupos de ángeles, y al frente del grupo de la derecha del trono está el 
diablo representado con una red en una mano y un arco en la otra, elementos que ni el texto ni la glosa explican ${ }^{50}$.

La segunda imagen que encontramos en Esc. I-I-5 corresponde a Jb 1:15. Fusiona dos imágenes que se leen de derecha a izquierda, según el orden hebreo: la muerte de los pastores, el robo de sus ganados y el mensajero que lo anuncia a Job en su casa: «E echose en çelada sola e tomolos e a los mançebos mataron a boca de espada e escapé yo en mi cabo por denunçiarlo a ty». Lo mismo sucede con Job 1:1-19: las viñetas se leen de derecha a izquierda. En primer lugar se ve la catástrofe y a la izquierda Job, sentado, escucha al mensajero que la relata. En todas las miniaturas Job mantiene la calma y el tocado sobre su cabeza salvo en la última, en la que tras conocer la muerte de sus hijos aparece con la cabeza descubierta y rasgándose las vestiduras, acto que se narra justo al pie de la imagen.

Si la primera imagen del manuscrito se explica por dejar clara la orientación cristiana de esta biblia, la presencia de la serie completa sobre las catástrofes que afligieron a Job, aunque dispuesta en un orden narrativo-visual propio del mundo hebreo, responde al gran interés que este tema despertó en la edad media castellana, como ejemplo de la mudanza de la fortuna y la necesaria resignación y confianza en $\operatorname{Dios}^{51}$.

\section{Recapitulando}

Todos los casos mencionados hasta este punto traen a colación el diálogo que el destinatario del manuscrito mantuvo con los copistas e iluminadores, que fueron los responsables de la incardinación de las ilustraciones con el texto al que aludían, de forma que en la página que se ofrecía a la vista del lector unos y otros estuvieran unidos y sirvieran para facilitar la comprensión del texto y no solamente a embellecer el libro.

Del examen de los ejemplos expuestos se pone en evidencia que la imagen funciona como glosa o explicación del texto que ilustra y por ello está siempre situada junto al versículo al que alude. Su posición informa de si pertenece a la fase inicial del proyecto iconográfico (Arragel, Esc. I-I-7, I-I-5 y también

\footnotetext{
${ }^{50}$ Notese que la glosa del f. 427rb está incompleta «e la egleja tiene que fue de la generaçión de». Queda espacio en la línea para añadir varias palabras, lo que hace suponer que Mosé Arragel esperaba que la completaran sus colaboradores cristianos. No emplearemos como término de comparación otras miniaturas del libro de Job correspondientes a la Biblia de Arragel porque la complejidad de su programa iconográfico requeriría un estudio independiente.

${ }^{51}$ Cfr. Gemma Avenoza, «Job: patriarca, santo y ejemplo de la mutación de la fortuna» en Les literatures antigues a les literatures medievals II. Herois i sants a la tradició literària occidental, ed. de A. Narro y J. Redondo, Amsterdam, A. M. Hakkert Publisher, 2012, pp. 1-20.
} 
I-I-3, caso que no hemos tratado aquí en detalle) o si responde a una petición posterior del destinatario de la copia (Esc. I-I-4). La elección de los temas a ilustrar nos plantea problemas difícilmente resolubles fuera de alguna conjetura razonable, como, por ejemplo, el que se ilustre más comúnmente Gé y Éx por tratarse de libros para los que existían no sólo modelos iconográficos cristianos sino también judíos (argumento aplicable a Esc. I-I-7), o el hecho de que se ilustren pasajes que remarcan la ortodoxia cristiana del volumen (representación de Dios como Jesucristo en Esc. I-I-5 y Arragel) y, por último pero no menos interesante, el que los motivos elegidos respondan a un interés especial del patrón: la historia de Job (en Esc. I-I-5); resultando más difícil de explicar las miniaturas sobre Dina y Balaam a no ser que se pretenda realizar una censura de costumbres (en Esc. I-I-4). La presencia de unos u otros motivos no se puede achacar al azar en modo alguno, más si tenemos en cuenta el rigor con el que se redactaban los contratos entre las partes cuando de copiar e iluminar un libro se trataba ${ }^{52}$.

Recibido: 29/03/2016

Aceptado: 7/06/2016

${ }^{52}$ Cfr. Jonathan J. G. Alexander, Medieval Illuminators and their Methods of Work, New Haven \& London, Yale University Press, 1992, con el texto del contrato para la llamada Biblia dos jerónimos (Venecia 1494) hoy en Lisboa, Aquivo da Torre do Tombo, en las pp. 181-182, o el firmado en 1422 en Valencia por el que Mosén Pere Cardona, presbítero, se comprometió a copiar una Vita Chisti del Cartujano para el prior de la Cartuja de Portacoeli, Francesc Maresme, según una muestra de escritura que el copista ha presentado y estableciéndose estrictas condiciones para el cumplimiento del encargo $c f r$. Francisco Gimeno Blay, «Entre el autor y el lector: producir manuscritos en catalán (siglos XII-XV)» en Anuario de Estudios Medievales, 37:1 (2007), pp. 305-366, el contrato en las pp. 334-335. 
$\cos$

IMAGEN Y TEXTO EN MANUSCRITOS BÍBLICOS HISPÁNICOS

RESUMEN: El ensayo aborda el estudio de un pequeño grupo de manuscritos bíblicos castellanos (Biblia de Arragel, Esc. I-I-4, I-I-5 e I-I-7) a partir de una perspectiva dialógica entre texto e imagen. Las miniaturas de un códice no solo son formas de embellecimiento material, sino también elementos surgidos para colmar determinadas expectativas de los patrones que encargaron los libros. Sirven de expresión iconográfica a un pensamiento que no se manifiesta con palabras y que nace del entorno en el que se produjo la copia e iluminación del manuscrito.

Palabras Clave: Romanceamientos Bíblicos. Codicología. Iconografía.

\section{TeXt and Image in HisPanic Biblical Manuscripts}

ABSTRACT: This essay studies a small group of Castilian biblical manuscripts (Arragel's Bible, Esc. I-I-4, I-I-5 and I-I-7) from a dialogic perspective between text and image. The miniatures of a codex are not only forms of material embellishment, but also elements emerged to fulfill certain expectations of patrons who commissioned books. They serve as iconographic expression of a thought that is not manifested in words and that have its origin in the milieu in which the copy and the illumination of the manuscript was produced.

Keywords: Medieval Biblical Translations. Codicology. Iconography. 